\title{
circRNA RNF111 regulates the growth, migration and invasion of gastric cancer cells by binding to miR-27b-3p
}

\author{
ZHIBING WANG $^{1 *}$, ZONGDAN JIANG $^{1 *}$, JIN ZHOU $^{2}$ and ZHENG LIU ${ }^{3}$ \\ Departments of ${ }^{1}$ Gastroenterology and ${ }^{2}$ General Surgery, Nanjing First Hospital, \\ Nanjing Medical University, Nanjing, Jiangsu 210006; ${ }^{3}$ Medical Center for Digestive Diseases, \\ Second Affiliated Hospital, Nanjing Medical University, Nanjing, Jiangsu 210011, P.R. China
}

Received February 25, 2020; Accepted July 30, 2020

DOI: $10.3892 / \mathrm{ijmm} .2020 .4709$

\begin{abstract}
RNA ring finger protein 111 (RNF111)] has been found to promote cancer growth; however, its role in gastric cancer (GC) remains unclear. The present study examined the effects of circR-RNF111 on the growth, migration and invasion of GC cells and aimed to elucidate the underlying molecular mechanisms. The expression levels of circR-RNF111 and miR-27b-3p in GC tissues and GC cell lines were detected by reverse transcription-quantitative PCR (RT-qPCR). StarBase v2.0 and dual-luciferase assay were used to predict and analyze the association between circR-RNF111 and miR-27b-3p. The effects of circR-RNF111 and miR-27b-3p on cell growth, apoptosis, migration and invasion were detected by cell counting kit-8 (CCK-8) assay, colony formation assay, flow cytometry, wound-healing assay and Transwell assay, respectively. In addition, western blot analysis was performed to determine the expression levels of genes related to cell apoptosis and epithelial-mesenchymal transition (EMT). The results revealed that circR-RNF111 and miR-27b-3p were closely related to the clinicopathological characteristics of GC, and that circR-RNF111 and miR-27b-3p negatively correlated and were abnormally expressed in GC. circR-RNF111 acted as a sponge of miR-27b-3p. The silencing of circR-RNF111 significantly inhibited GC cell viability, colony formation, migration and invasion, and exerted a pro-apoptotic effect. miR-27b-3p inhibitor promoted
\end{abstract}

Correspondence to: Dr Zheng Liu, Medical Center for Digestive Diseases, Second Affiliated Hospital, Nanjing Medical University, 121 Jiangjiayuan, Gulou, Nanjing, Jiangsu 210011, P.R. China E-mail: liuzheng117@njmu.edu.cn

${ }^{*}$ Contributed equally

Abbreviations: RNF111, ring finger protein 111; GC, gastric cancer; RT-qPCR, reverse transcription-quantitative PCR; HCC, hepatocellular carcinoma; EMT, epithelial-mesenchymal transition

Key words: circRNA RNF111, gastric cancer, miR-27b-3p, apoptosis, proliferation the proliferation, migration and invasion of GC cells, and inhibited cell apoptosis. In addition, circR-RNF111 silencing significantly decreased the expression levels of Bcl2, Vimentin and $\mathrm{N}$-cadherin, and increased those of cleaved caspase- 3 and E-cadherin. Furthermore, miR-27b-3p inhibition reversed the regulatory effects of circR-RNF111 silencing on the GC cells. On the whole, the findings of the present study demonstrate that circR-RNF111 is involved in the regulation of growth, migration and invasion of GC cells by binding to miR-27b-3p.

\section{Introduction}

Gastric cancer (GC) results in a high mortality rate in China (1). At present, the diagnosis of GC is largely based on clinical symptoms in combination with physical signs and endoscopy, B-mode ultrasound, CT examination and exfoliative cytology (2), which, however, all have certain defects. In addition, symptoms are not always obvious at the early stages of GC (3). Numerous GC patients are already in the advanced stages of the disease by the time of diagnosis, and thus face a greater risk of developing recurrence and metastasis following surgical resection (4). Therefore, improving the understanding of the molecular mechanisms of GC proliferation and metastasis will facilitate the discovery of novel biomarkers and therapeutic targets for the treatment of GC.

circRNAs have stable structures and have recently attracted ample research attention (5). Compared with linear RNAs, circRNAs are not easily degraded by exonucleases, they are highly conserved and remain stable in vivo, which suggests that circRNAs have the potential to function as diagnostic markers (6). circRNAs primarily function as miRNA 'sponges', containing numbers and types of miRNA response elements at varying degrees $(5,7)$. circRNAs can bind to specific miRNAs and competitively inhibit the binding of the miRNA to the corresponding site, and subsequently regulate the expression of downstream target genes (7). Zhong et al demonstrated that circRNA MYLK functions a competitive endogenous RNA in bladder cancer (8). The overexpression of circRNA MYLK in bladder cancer cell lines can significantly reduce the expression of miR-29a (8).

circRNAs play crucial roles in a variety of cancers by functioning as tumor suppressor genes or oncogenes, suggesting their potential to serve as tumor biomarkers (9). Han et al 
analyzed the expression profiles of circRNAs in hepatocellular carcinoma (HCC) tissues, and found that patients with a low expression of circMTO1 had a shorter survival time, suggesting that it may be a tumor suppressor (10). Furthermore, miR-9, which is a circMTO1-related miRNA, was found to downregulate $\mathrm{p} 21$ expression, and promote the proliferation and invasion of HCC cells (10). A previous study found that miRNAs can regulate the expression of almost $2 / 3$ of human proteins, and $>50 \%$ of miRNAs are located in tumor-associated genomic regions (11). Chromosomal abnormalities directly lead to alterations in gene copy numbers, resulting in an abnormal expression in various tumors. The indispensable roles of miRNAs and circRNAs in the development of GC have been previously observed $(6,12)$.

The high expression of hsa_circ_0001982 (circRNA RNF111) has been shown to promote the proliferation and migration of breast cancer cells (13). In addition, lncRNA UCA1 can enhance the multidrug resistance of GC by downregulating miR-27b expression (14). However, whether circRNA RNF111 is also regulated by miR-27b expression and whether it is involved in GC remains to be determined. Therefore, the present study examined the association between circRNA RNF111 and miR-27b by investigating their potential molecular mechanisms and their biological effects on GC.

\section{Materials and methods}

Ethics statement. The GC tissues were obtained from 48 patients who were diagnosed with GC at the Nanjing First Hospital from November, 2018 to November, 2019. All the patients signed informed consent forms, and agreed that their tissues would be used for clinical research. The clinical trial program had been reviewed and approved by the Ethics Committee of Nanjing First Hospital (W201810013).

Tissues, cell lines and culture. The GC tissues and their corresponding normal adjacent tissues (at least $5 \mathrm{~cm}$ away from the tumor) were collected from 48 patients with GC. Human normal gastric mucosa cells (GES-1, CS0097, Beijing Dingguo Changsheng Biotechnology Co., Ltd.) and GC cell lines [AGS (CRL-1739, ATCC), SNU-16 (CRL-5974, ATCC), MNK-45 (CS0096, Beijing Dingguo Changsheng Biotechnology Co., Ltd.) and HGC27 (94042256, Sigma; Merck KGaA)] were used in the present study.

The cells were cultured in DMEM (12491015, Thermo Fisher Scientific, Inc.) supplemented with $10 \%$ fetal bovine serum (FBS, 30067334), 1\% penicillin/streptomycin (15140163) at $37^{\circ} \mathrm{C}$ with $5 \% \mathrm{CO}_{2}$ for 1 day. Following culture, the primary medium was discarded, and the cells were washed with PBS 1-2 times; fresh DMEM medium $(5 \mathrm{ml})$ was then added and the cells were returned to the $\mathrm{CO}_{2}$ incubator. The cells were sub-cultured after 80 to $90 \%$ of them had adhered to the wall.

Cell transfection. After 12 to $16 \mathrm{~h}$, the cells reached 60 to $70 \%$ confluency and were transfected with liposome. circRNA siRNF111 (5'-UAAGGAAAGCCUGAG GGA AC-3'), siNC (siN0000001-1-5) and miR-27b-3p inhibitor (miR20000419-1-5), inhibitor negative control (miR2N0000001-1-5) were purchased from Guangzhou
RiboBio Co., Ltd. Cell transfection was performed according to the protocol of the manufacturer of Lipofectamine 3000 (L3000015, Thermo Fisher Scientific, Inc.). In brief, after the seeded cells reached $70-90 \%$ fusion and were ready for transfection, Lipofectamine 3000 reagent and RNA (100 ng/well) were diluted in Opti-MEM medium, respectively. The diluted Lipofectamine 3000 reagent was added with the diluted RNA was added at 1:1. Following incubation of the mixture for $10 \mathrm{~min}$ at room temperature, the RNA-lipid complex was added to the cells and incubated for 2 days at $37^{\circ} \mathrm{C}$. Finally, the transfected cells were further analyzed.

Bioinformatics assay. The latent binding sites between circR-RNF111 and miR-27b-3p were predicted using Starbase v2.0 (http://starbase.sysu.edu.cn/).

Dual-luciferaseactivityassay.WT-RNF111 and MUT-RNF111 DNA were cloned into pmirGLO luciferase Vectors (E1330; Promega Corporation). To analyze the latent binding sites between circRNA RNF111 and miR-27b-3p, 293T cells (CRL-11268, ATCC) were transfected with miR-27b-3p mimic or inhibitor. The luciferase activity was determined using a Double-Luciferase Reporter Assay kit (FR201-01, Beijing Transgen Biotech Co., Ltd.). Briefly, the cell culture medium was removed, and the cells were cautiously rinsed twice in PBS and then fully lysed by $100 \mu$ l Cell Lysis Buffer for $10 \mathrm{~min}$ at room temperature. The supernatant was obtained by centrifuging the cells at $12,000 \mathrm{x} \mathrm{g}$ at $4^{\circ} \mathrm{C}$ for $10 \mathrm{~min}$. Luciferase Reaction Reagent $(100 \mu \mathrm{l})$ was added to the centrifugal tube at room temperature, cell lysates $(20 \mu \mathrm{l})$ were cautiously pipetted into the tube, and the two were then gently mixed. The Firefly luciferase reporter gene activity was measured using a luminescence meter (SpectraMaxL, Molecular Devices, LLC). Finally, Luciferase Reaction Reagent II (100 $\mu$ l) was added to the above-mentioned reaction tube at room temperature, vortexed, and the activity of the Renilla luciferase reporter gene was determined using a luminescence meter.

Reverse transcription-quantitative PCR (RT- $q P C R)$. Total RNA was extracted from the GC tissues and cells using the TRIzol method at $4^{\circ} \mathrm{C}$. The reverse transcription of the RNA was performed using the MicroRNA Reverse Transcription kit (4366597, Thermo Fisher Scientific, Inc.) according to the manufacturers' protocol. For regent preparation, briefly, $1.5 \mu \mathrm{l}$ total RNA (10-200 ng), $2.0 \mu 1$ One-Color Spike Mix for Cyanine 3-labeling, $0.8 \mu 1 \mathrm{~T} 7$ Promoter Primer and $1.0 \mu \mathrm{l}$ RNase free water were thoroughly mixed at $65^{\circ} \mathrm{C}$ for $10 \mathrm{~min}$ and then reacted in ice bath for $5 \mathrm{~min}$ to form the Reaction 1. The Reaction 2 was composed of $2.0 \mu 15 X$ First Strand Buffer, $1.0 \mu 10.1$ M DTT, $0.5 \mu 110 \mathrm{~m} \mathrm{M} \mathrm{d} \mathrm{NTP} \mathrm{mix,} \mathrm{and} 1.2 \mu \mathrm{l}$ Affinity Script RNase Block Mix. The Reaction 1 was then mixed with the Reaction 2 at $40^{\circ} \mathrm{C}$ for $120 \mathrm{~min}$, at $70^{\circ} \mathrm{C}$ for $5 \mathrm{~min}$, and at $4^{\circ} \mathrm{C}$ for $5 \mathrm{~min}$.qPCR was performed according to the instructions of the detection system (ABI 7500, Life Technologies; Thermo Fisher Scientific, Inc.). The relative expression levels were calculated using the $2^{-\triangle \Delta C q}$ method (15). GAPDH was used as a housekeeping gene for mRNA, and U6 as an internal control for miRNA. The primer sequences were as follows: miR-27b-3p forward, 5'-AGT GGCTAAGTTCTGCGTCG-3' and reverse, 5'-GTATCCAGT GCGTGTCGTGG-3'; RNF111 forward, 5'-TAGCAGTTCCCC 
AATCCTTG-3' and reverse, 5'-CACAAATTCCCATCATTC CC-3'; GAPDH forward, 5'-TGTGGGCATCAATGGATT TGG-3' and reverse, 5'-ACACCATGTATTCCGGGTCAAT-3'; and U6 forward, 5'-AAAGCAAATCATCGGACGACC-3' and reverse, 5'-GTACAACACATTGTTTCCTCGGA-3'.

CCK-8 assay. The GC cells $\left(1 \times 10^{4} /\right.$ well) were added to a 96-well plate and incubated for $24 \mathrm{~h}$ at $37^{\circ} \mathrm{C}$. Following transfection for 12, 24 and $48 \mathrm{~h}, 10 \mu \mathrm{l} \mathrm{CCK-8} \mathrm{solution} \mathrm{(HY-K0301,}$ MedChemExpress) was cultured with the cells for $2-4 \mathrm{~h}$ at $37^{\circ} \mathrm{C}$. The absorbance (at $450 \mathrm{~nm}$ ) was detected using a microplate reader (24072800, Thermo Fisher Scientific, Inc.).

Colony formation assay. The monolayer cultured cells $(250 / \mathrm{ml})$ at logarithmic growth phase were collected, digested with $0.25 \%$ trypsin at room temperature for 3-4 min and pipetted into individual cells. The cells were suspended in a culture solution containing 10\% FBS, and the cell suspension was diluted and then inoculated in DMEM. The culture was terminated when macroscopic clones appeared in the dish. The supernatant was discarded and the cells were carefully rinsed twice with PBS. At room temperature, acetic acid/methanol at 1:3 was used to fix the cells for $15 \mathrm{~min}$. After removing the fixation solution, the cells were properly stained with Giemsa (Beyotime Institute of Biotechnology, Inc.) at room temperature for $25 \mathrm{~min}$. The cell clones were counted with the naked eye and the colony formation rate was calculated as follows: Clonal formation rate $=$ (number of clone formation/number of cells inoculated) $\mathrm{x} 100 \%$.

Flow cytometry. The AGS and SNU-16 cells $\left(1 \times 10^{6}\right)$ were prepared as a single dispersed cell suspension. Before testing the machine, $5 \mu \mathrm{l}$ Annexin V-FITC and $5 \mu \mathrm{l}$ PI staining solution were added to the suspension for $15 \mathrm{~min}$ in the dark at room temperature using the test kit (MA0220, Melone Pharmaceutical Co., Ltd.). Cell apoptosis was determined using a FACSCalibur flow cytometer (FACSCalibur, BD Biosciences) and FlowJo software (version 10.0; FlowJo). The lower left quadrant (AnnexinV $\left.{ }^{-}, \mathrm{PI}^{-}\right)$represented healthy living cells; the upper left quadrant $\left(\mathrm{AnnexinV}^{-}, \mathrm{PI}^{+}\right)$represented dead cells; the lower right quadrant $\left(\mathrm{AnnexinV}^{+}, \mathrm{PI}^{-}\right)$ represented early apoptotic cells; and the upper right quadrant $\left(A n n e x i n V^{+}, \mathrm{PI}^{+}\right)$represented late apoptotic cells.

Wound healing assay. The AGS and SNU-16 cells were seeded at a density of $1 \times 10^{4}$ into a 96 -well plate for $24 \mathrm{~h}$ at $37^{\circ} \mathrm{C}$. The cell culture layer was scratched using a sterile sampler tip, the floating cells were washed away with PBS, and the cells were cultured in serum-free DMEM medium for $24 \mathrm{~h}$ at $37^{\circ} \mathrm{C}$. Cell migration images were observed under a microscope (BZ-8100, Keyence) and the migration distance was observed using Image-pro Plus 4.1 analysis software (Media Cybernetics, Inc.).

Transwell assay. The invasive ability of the AGS and SNU-16 cells was detected by 24-well Transwell plates (CLS3398, Sigma; Merck KGaA). The cells ( $5 \times 10^{4}$ cells/well) were seeded into the upper chamber pre-coated with $200 \mathrm{mg} / \mathrm{ml}$ Matrigel (354230, BD Biosciences), and the upper chamber was supplemented with serum-free medium. The lower chamber was supplemented with $10 \%$ serum medium to form a nutrient concentration gradient, which promoted the cell invasion into the lower chamber. Following incubation for $24 \mathrm{~h}$ at $37^{\circ} \mathrm{C}$, the cells were fixed with $4 \%$ paraformaldehyde and stained with $0.1 \%$ crystal violet (Beyotime Institute of Biotechnology, Inc.) for $20 \mathrm{~min}$ at room temperature. Cell numbers in each group were counted from 4 fields of view under an inverted microscope (CKX41, Olympus Corporation)

Western blot analysis. The GC cells was separated using RIPA lysate (89901, Thermo Fisher Scientific, Inc.), and the protein concentration was determined using a Protein Assay kit(A53227, Thermo Fisher Scientific, Inc.). A volume of $30 \mu \mathrm{g}$ proteins of each tissue was separated on $10 \%$ SDS-polyacrylamide gels and transferred to a PVDF membrane (HVLP04700, EMD Millipore), which the membrane was then washed with TBS and blocked with $5 \%$ non-fat milk at $37^{\circ} \mathrm{C}$ for $1 \mathrm{~h}$ and shaken for $2 \mathrm{~h}$ at room temperature. The membrane was then incubated with the following primary antibodies: Anti-Bcl2 (1:1,000; $26 \mathrm{kDa}$; rabbit; ab32124), anti-procaspase-3 (1:10,000; $35 \mathrm{kDa}$; rabbit; ab32499), anti-cleaved caspase-3 (1:500; $17 \mathrm{kDa}$; rabbit; ab32042), Vimentin (1:1,000; 54 kDa; rabbit; ab92547), $\mathrm{N}$-cadherin $(1 \mu \mathrm{g} / \mathrm{ml} ; 130 \mathrm{kDa}$; rabbit; ab18203), E-cadherin (1:10,000; $97 \mathrm{kDa}$; rabbit; ab40772) or GAPDH (1:10,000; $36 \mathrm{kDa}$; rabbit; ab181602) (all from Abcam) overnight at $4^{\circ} \mathrm{C}$. The target band was incubated with a goat anti-rabbit IgG H\&L (HRP) (1:5,000; ab205718; Abcam) for $2 \mathrm{~h}$ at room temperature. Finally, the signals were measured by ECL reagent (6883, Cell Signaling Technology, Inc.), and the gray values of the bands were analyzed and counted using ImageJ software (version 5.0, Bio-Rad Laboratories, Inc.) (16).

Statistical analysis. The data are presented as the means \pm SD . Comparisons between groups were conducted using a paired Student's $t$ test or one-way analysis of variance (ANOVA), followed by Dunnett's test or Tukey's test. The Chi-square test or rank sum test were used to analyze the data presented in Table I. All the data were analyzed using GraphPad Prism 7.0 software. The correlation between circRNA RNF111 and miR-27b-3p in GC was analyzed by Pearson's correlation analysis. A P $<0.05$ was considered to indicate a statistically significant difference.

\section{Results}

CircR-RNF111 and miR-27b were negatively correlated and were abnormally expressed in $G C$. The associations between circRNA RNF111, miR-27b-3p and the pathological characteristics of the clinical samples obtained from the patients with GC were analyzed. The results revealed that the high expression of circR-RNF111 and the low expression of miR-27b-3p were significantly and positively associated with tumor size, stage, lymphatic metastasis, distant metastasis and invasion (Table I). The expression levels of the 2 genes in GC and normal samples were then compared, and it was found that the expression of circRNA RNF111 in the GC tissues was significantly higher than that in adjacent normal tissues $(\mathrm{P}<0.001$; Fig. $1 \mathrm{~A})$, whereas the expression level of miR-27b-3p was markedly lower in GC tissues than in adjacent normal tissues $(\mathrm{P}<0.001$; Fig. 1B). Pearson's correlation curve analysis demonstrated 
Table I. Association between circRNA RNF111 and miR-27b-3p and clinicopathological characteristics of patients with gastric cancer.

\begin{tabular}{|c|c|c|c|c|c|c|c|}
\hline \multirow[b]{2}{*}{ Characteristic } & \multirow[b]{2}{*}{ Total } & \multicolumn{2}{|c|}{$\begin{array}{l}\text { circRNA RNF111 } \\
\text { expression }\end{array}$} & \multirow[b]{2}{*}{ P-value } & \multicolumn{2}{|c|}{$\begin{array}{l}\text { miR-27b-3p } \\
\text { expression }\end{array}$} & \multirow[b]{2}{*}{ P-value } \\
\hline & & Low $n=24$ & High $n=24$ & & Low $n=24$ & High n=24 & \\
\hline Sex & & & & 0.763 & & & 0.365 \\
\hline Male & 31 & 15 & 16 & & 17 & 14 & \\
\hline Female & 17 & 9 & 8 & & 7 & 10 & \\
\hline Age (years) & & & & 0.551 & & & 0.233 \\
\hline$\leq 60$ & 18 & 8 & 10 & & 7 & 11 & \\
\hline$>60$ & 30 & 16 & 14 & & 17 & 13 & \\
\hline Location & & & & 0.772 & & & 0.487 \\
\hline Cardia & 9 & 4 & 5 & & 6 & 3 & \\
\hline Body & 5 & 3 & 2 & & 2 & 3 & \\
\hline Curvature & 6 & 2 & 4 & & 4 & 2 & \\
\hline Antrum & 28 & 15 & 13 & & 12 & 16 & \\
\hline Tumor size (cm) & & & & 0.001 & & & $<0.001$ \\
\hline$\geq 5 \mathrm{~cm}$ & 14 & 2 & 12 & & 13 & 1 & \\
\hline$<5 \mathrm{~cm}$ & 34 & 22 & 12 & & 11 & 23 & \\
\hline Histological differentiation & & & & 0.490 & & & 0.300 \\
\hline Well & 5 & 3 & 2 & & 1 & 4 & \\
\hline Moderate & 13 & 8 & 5 & & 6 & 7 & \\
\hline Poor & 30 & 13 & 17 & & 17 & 13 & \\
\hline TNM stage & & & & 0.002 & & & 0.014 \\
\hline I & 11 & 9 & 2 & & 3 & 8 & \\
\hline II & 10 & 8 & 2 & & 2 & 8 & \\
\hline III & 22 & 5 & 17 & & 16 & 6 & \\
\hline IV & 5 & 2 & 3 & & 3 & 2 & \\
\hline Lymph node metastasis & & & & 0.001 & & & 0.008 \\
\hline Yes & 36 & 13 & 23 & & 22 & 14 & \\
\hline No & 12 & 11 & 1 & & 2 & 10 & \\
\hline Distant metastasis & & & & 0.004 & & & 0.033 \\
\hline Yes & 10 & 1 & 9 & & 8 & 2 & \\
\hline No & 38 & 23 & 15 & & 16 & 22 & \\
\hline Depth of invasion & & & & $<0.001$ & & & 0.007 \\
\hline $\mathrm{m}$ & 9 & 8 & 1 & & 2 & 7 & \\
\hline $\mathrm{sm}$ & 10 & 9 & 1 & & 3 & 7 & \\
\hline $\mathrm{mp}$ & 7 & 3 & 4 & & 2 & 5 & \\
\hline se, sei & 22 & 4 & 18 & & 17 & 5 & \\
\hline
\end{tabular}

$\mathrm{m}$, carcinomas were confined to the mucosa and did not invade the submucosa; sm, carcinomas were confined to the submucosa and did not invade the muscularis propria; $\mathrm{mp}$, carcinomas is confined to the lamina propria and does not cross the muscularis propria; se, carcinomas penetrates the serosal surface; sei, carcinomas attacks other organs directly.

that circRNA RNF111 expression negatively correlated with miR-27b expression in GC tissues ( $\mathrm{r}=-0.352, \mathrm{P}=0.014$; Fig. 1C) and adjacent normal tissues ( $r=-0.379, P=0.008$; Fig. 1D).

miR-27b-3p is targeted to bind to circRNA RNF111. To explore the regulatory mechanisms of circR-RNF111 and miR-27b-3p in GC, starBase v2.0 was used to predict the potential binding site between circR-RNF111 and miR-27b-3p. The results revealed that circRNA RNF111 has a binding site specific for miR-27b-3p (Fig. 2A). The binding site between these 2 factors 293T cells was verified by dual luciferase assay, and the data indicated that miR-27b-3p effectively reduced the fluorescence activity of wild-type RNF111, whereas it did not affect that of the mutant RNF111 fluorescent plasmid ( $\mathrm{P}<0.01$; Fig. 2B); miR-27b-3p 
A

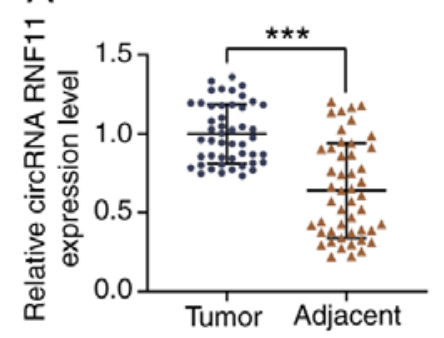

B

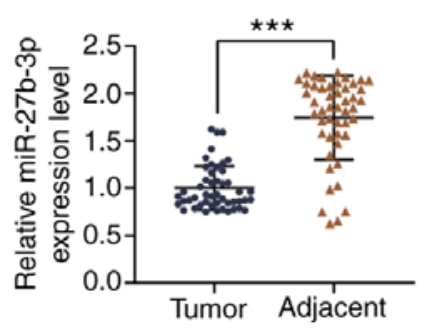

C

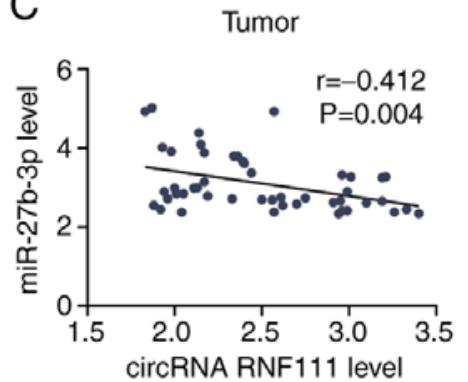

D

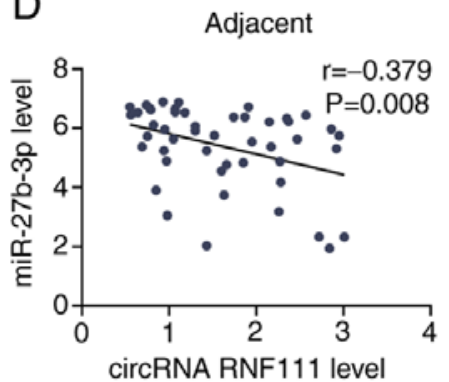

Figure 1. Expression and correlation analysis of circRNA RNF111 and miR-27b-3p in clinical GC tissues. (A and B) RT-qPCR was used to detect the expression levels of circRNA RNF111 and miR-27b-3p in 48 pairs of clinical gastric cancer tissues and adjacent normal tissues. (C and D) Pearson's correlation curve analysis of the correlation between circR-RNF111 and miR-27b-3p in different tissues $(n=48)$. ${ }^{* * *} \mathrm{P}<0.001$ vs. tumor tissue. GC, gastric cancer; RT-qPCR, reverse transcription-quantitative polymerase chain reaction.

A

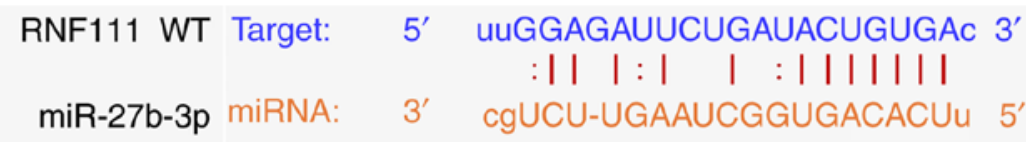

RNF111 MUT Target: $\quad 5^{\prime}$ uuGAGGGUGCUAAUCACUGAGc $3^{\prime}$

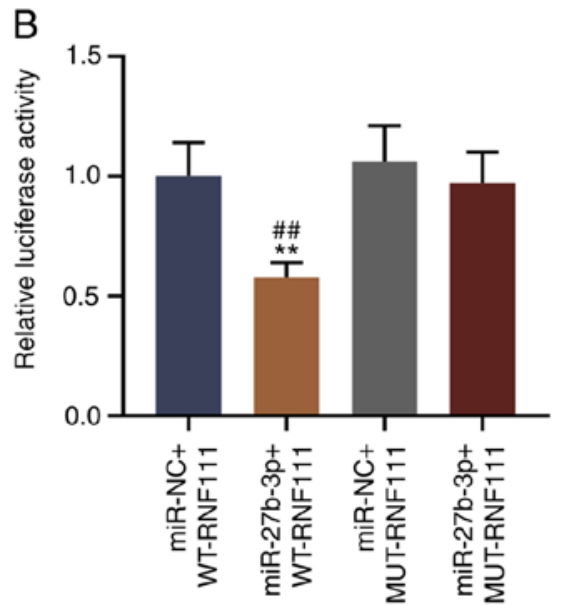

D

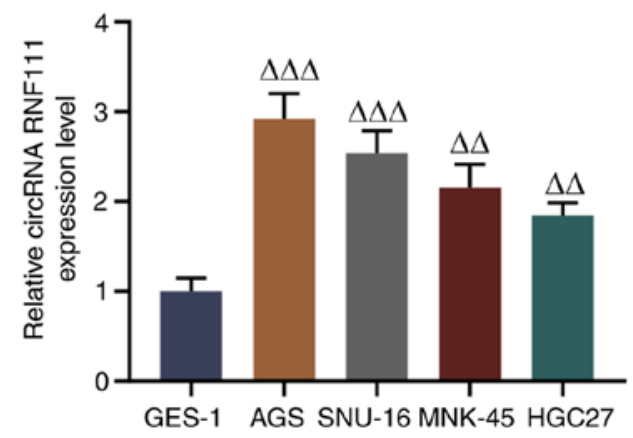

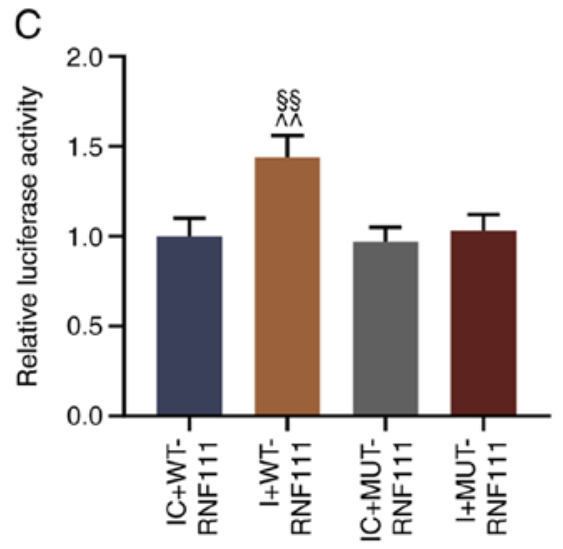

$E$

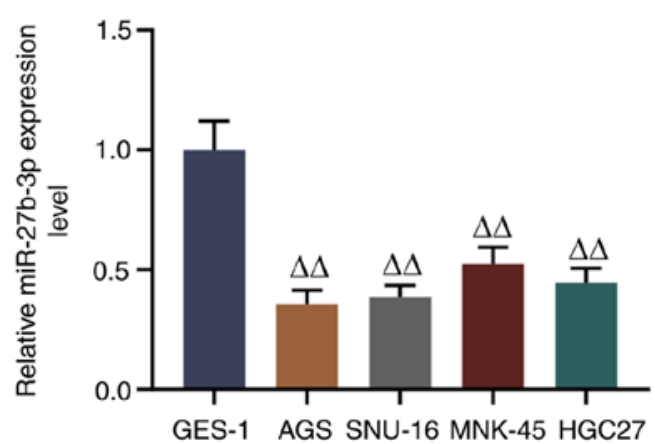

Figure 2. miR-27b-3p is targeted to bind to circRNA RNF111 and the 2 factors were abnormally expressed in GC cell lines. (A) StarBase v2.0, and (B and $\mathrm{C}$ ) dual luciferase activity were used to identify the miR-27b-3p binding sites in circRNA RNF111 ( ${ }^{* *} \mathrm{P}<0.01$ vs. miR-NC $+\mathrm{WT}-\mathrm{RNF} 111$; ${ }^{* \#} \mathrm{P}<0.01$ vs. miR-27b-3p + MUT-RNF111; ${ }^{\wedge} \mathrm{P}<0.01$ vs. IC + WT-RNF111; ${ }^{\S} \mathrm{P}<0.01$ vs. I + MUT-RNF111). (D and E) RT-qPCR detection of circR-RNF111 and miR-27b-3p normal gastric mucosal cells (GES-1) and gastric cancer cell lines (AGS, SNU-16, MNK-45 and HGC27). ${ }^{\Delta \Delta} \mathrm{P}<0.01,{ }^{\Delta \Delta \Delta} \mathrm{P}<0.001$ vs. GES-1 cells. GC, gastric cancer; IC, inhibitor control; I, inhibitor.

inhibitor increased the fluorescence activity of wild-type RNF111, whereas it did not affect that of the mutant RNF111 fluorescent plasmid $(\mathrm{P}<0.01$; Fig. 2C). Furthermore, the roles of RNF111 and miR-27b-3p in GC were further examined by detecting the expression levels of circR-RNF111 and miR-27b-3p in normal gastric mucosal cells (GES-1) and GC cell lines (AGS, SNU-16, MNK-45 and HGC27). It was also found that overall, circRNA RNF111 expression was high-expressed in the GC cell 
A

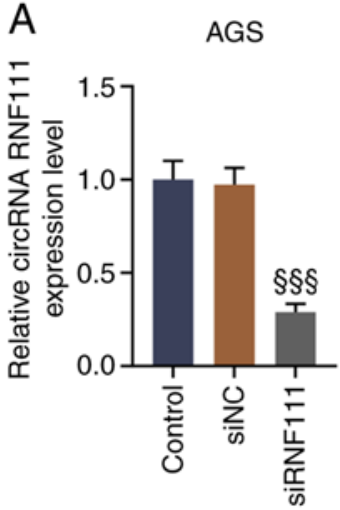

$\mathrm{E}$
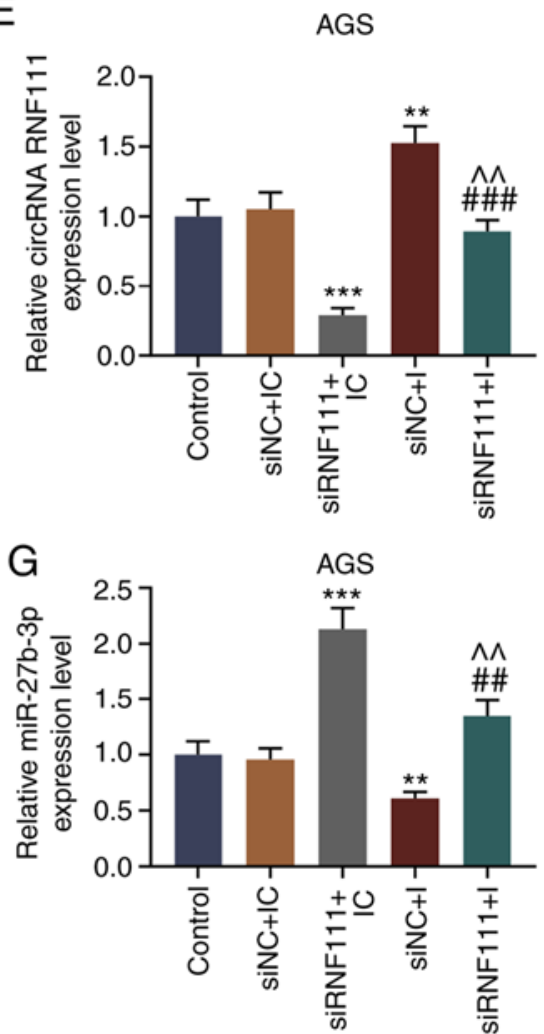

I

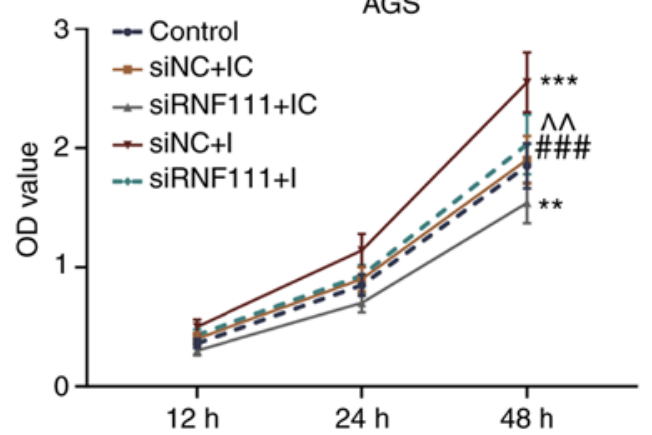

$\mathrm{B}$

SNU-16

AGS

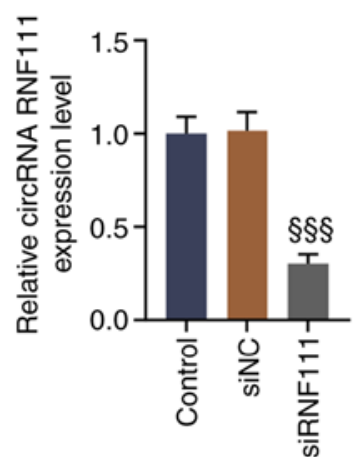

\section{$\mathrm{F}$}
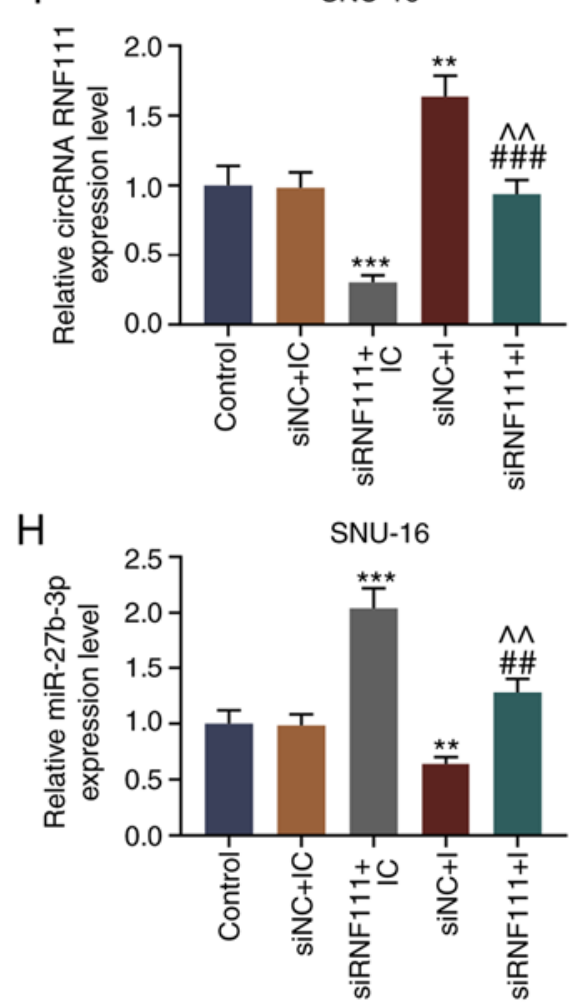

$J$

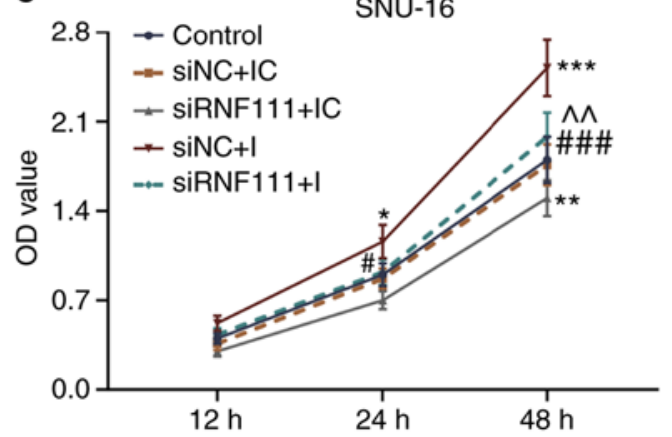

Figure 3. Effect of circRNA RNF111 silencing and miR-27b-3p inhibitor on the proliferation of GC cells. (A-D) RT-qPCR was used to detect the expression levels of circRNA RNF111 and miR-27b-3p after AGS or SNU-16 cells were transfected with Control, siNC, siRNF111, inhibitor control, or inhibitor. (E-H) RT-qPCR was used to detect the expression levels of circRNA RNF111 and miR-27b-3p after the AGS or SNU-16 cells were transfected with Control, siNC + inhibitor control, siRNF111 + inhibitor control, siNC + inhibitor, siRNF111 + inhibitor. (I and J) CCK-8 assay was used to examine the cell viability of each group. ${ }^{\S \S} \mathrm{P}<0.001$ vs. siNC, ${ }^{\Delta \Delta} \mathrm{P}<0.01$ vs. IC, ${ }^{*} \mathrm{P}<0.05,{ }^{* * *} \mathrm{P}<0.01,{ }^{* * *} \mathrm{P}<0.001$ vs. siNC $+\mathrm{IC},{ }^{\# P} \mathrm{P}<0.05,{ }^{\# \#} \mathrm{P}<0.01,{ }^{\# \# \#} \mathrm{P}<0.001$ vs. siRNF111 + IC, ${ }^{\wedge \wedge} \mathrm{P}<0.01$ vs. siNC + I. GC, gastric cancer; RT-qPCR, reverse transcription-quantitative polymerase chain reaction; IC, inhibitor control; I, inhibitor.

lines $(\mathrm{P}<0.01$; Fig. 2D), while miR-27b-3p expression was low in $\mathrm{GC}$ cells $(\mathrm{P}<0.01$; Fig. 2E). In addition, circRNA RNF111 expression was higher in the AGS and SNU-16 cells and miR-27b-3p expression was lower in the AGS and SNU-16 cells compared with the other GC cells; thus, these 2 cell lines were selected for use in subsequent experiments. 

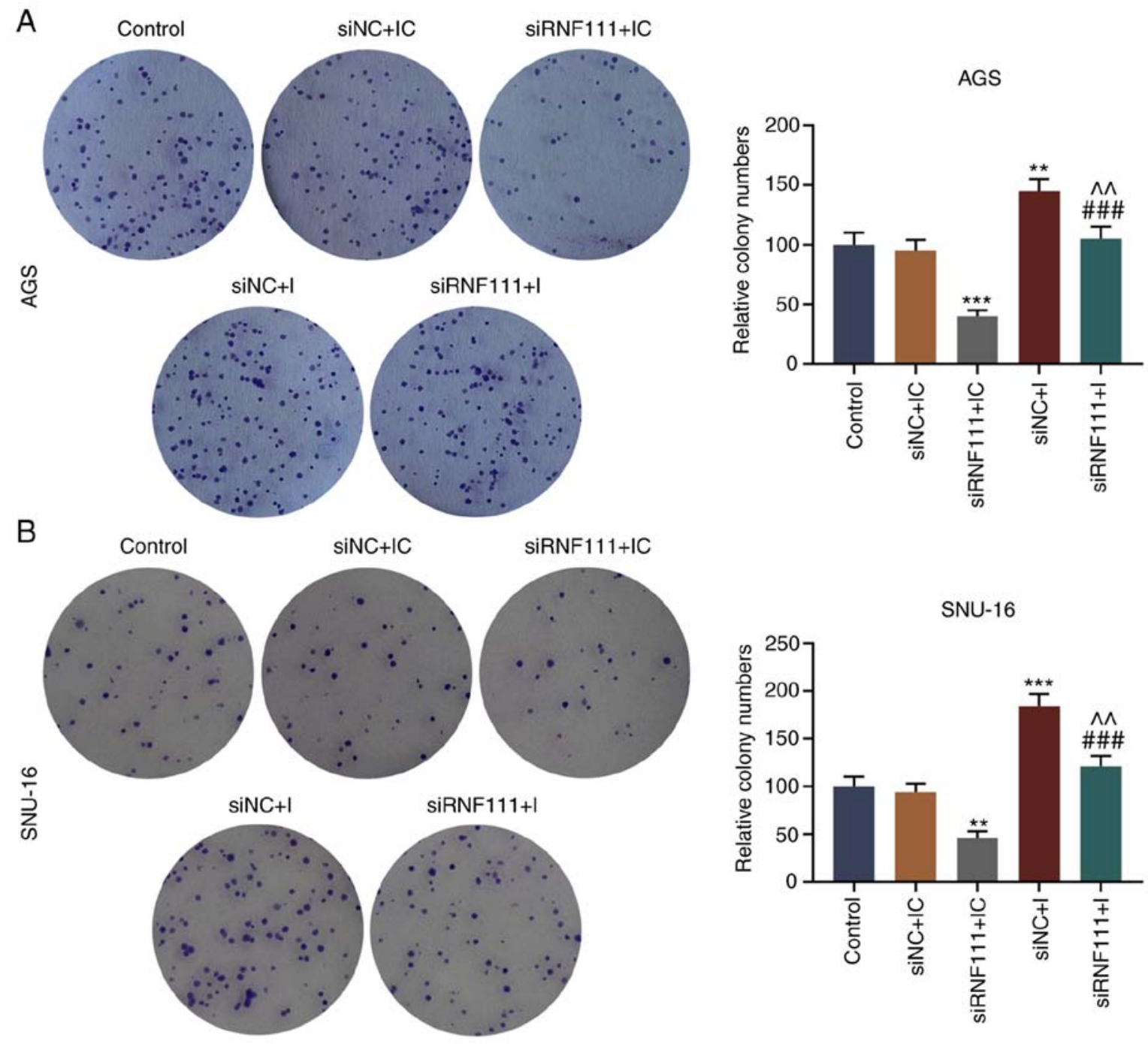

Figure 4. Effects of circRNA RNF111 and miR-27b-3p on the growth of GC cells. (A) The numbers of colony formation in AGS cells transfected with Control, siNC + inhibitor control, siRNF111 + inhibitor control, siNC + inhibitor, siRNF111 + inhibitor were determined by colony formation assay. (B) The numbers of colony formation in SNU-16 cells transfected with Control, siNC + inhibitor control, siRNF111 + inhibitor control, siNC + inhibitor, siRNF111 + inhibitor were determined by colony formation assay. ${ }^{* *} \mathrm{P}<0.01,{ }^{* * * *} \mathrm{P}<0.001$ vs. siNC $+\mathrm{IC},{ }^{\# \# \#} \mathrm{P}<0.001 \mathrm{vs}$. siRNF111 + IC, ${ }^{\wedge} \mathrm{P}<0.01 \mathrm{vs}$. siNC + I. GC, gastric cancer; IC, inhibitor control; I, inhibitor.

circRNA RNF111 binding to miR-27b-3p regulates the growth and apoptosis of GC cells. To examine the effects of circRNA RNF111 and miR-27b-3p on the biological functions of GC cells, circRNA siRNF111 and miR-27b-3p inhibitor were successfully transfected into the AGS cells and SNU-16 cells. As shown in Fig. 3A-D, in the AGS and SNU-16 cells, the results revealed that the expression of circRNA RNF111 was significantly lower in the siRNF111 group than in the siNC group $(\mathrm{P}<0.001)$, and miR-27b-3p expression was decreased in the inhibitor group $(\mathrm{P}<0.01)$. siRNA transfection significantly inhibited circRNA RNF111 expression and increased that of miR-27b-3p, while transfection with miR-27b-3p inhibitor partially reversed the siRNA regulatory effects on circRNA RNF111 and miR-27b-3p expression $(\mathrm{P}<0.01$; Fig. 3E-H). The results of CCK-8 assay revealed that circRNA RNF111 silencing markedly inhibited the viability of the GC cells, and transfection with miR-27b-3p inhibitor significantly increased the viability of the cells $(\mathrm{P}<0.01$; Fig. $3 \mathrm{I}$ and $\mathrm{J})$. Colony formation assay demonstrated that the silencing of circR-RNF111 significantly inhibited the colony formation of the cancer cells, and miR-27b-3p inhibitor noticeably reversed the inhibitory effects of circRNA RNF111 silencing on cell proliferation $(\mathrm{P}<0.001$; Fig. 4). Flow cytometry was then performed to measure the apoptosis of each group of cells; it was found that circRNA RNF111 silencing markedly promoted apoptosis, which was markedly reversed by miR-27b-3p inhibitor $(\mathrm{P}<0.05$; Fig. 5).

circR-RNF111 binding to miR-27b-3p regulates the metastasis of GC cells. To further examine the effects of circRNA RNF111 and miR-27b-3p on GC, a wound healing assay and Transwell invasion assay were performed. As shown in Fig. 6, circRNA RNF111 silencing significantly inhibited the migration of the GC cells, while miR-27b-3p inhibition promoted cell migration and effectively reversed the inhibitory effects induced by circRNA RNF111 silencing $(\mathrm{P}<0.05)$. In addition, circR-RNF111 silencing markedly decreased cell invasion, whereas miR-27b-3p inhibition promoted cell invasion and effectively reversed the inhibitory effects of circRNA RNF111 silencing ( $\mathrm{P}<0.01 ;$ Fig. 7). 

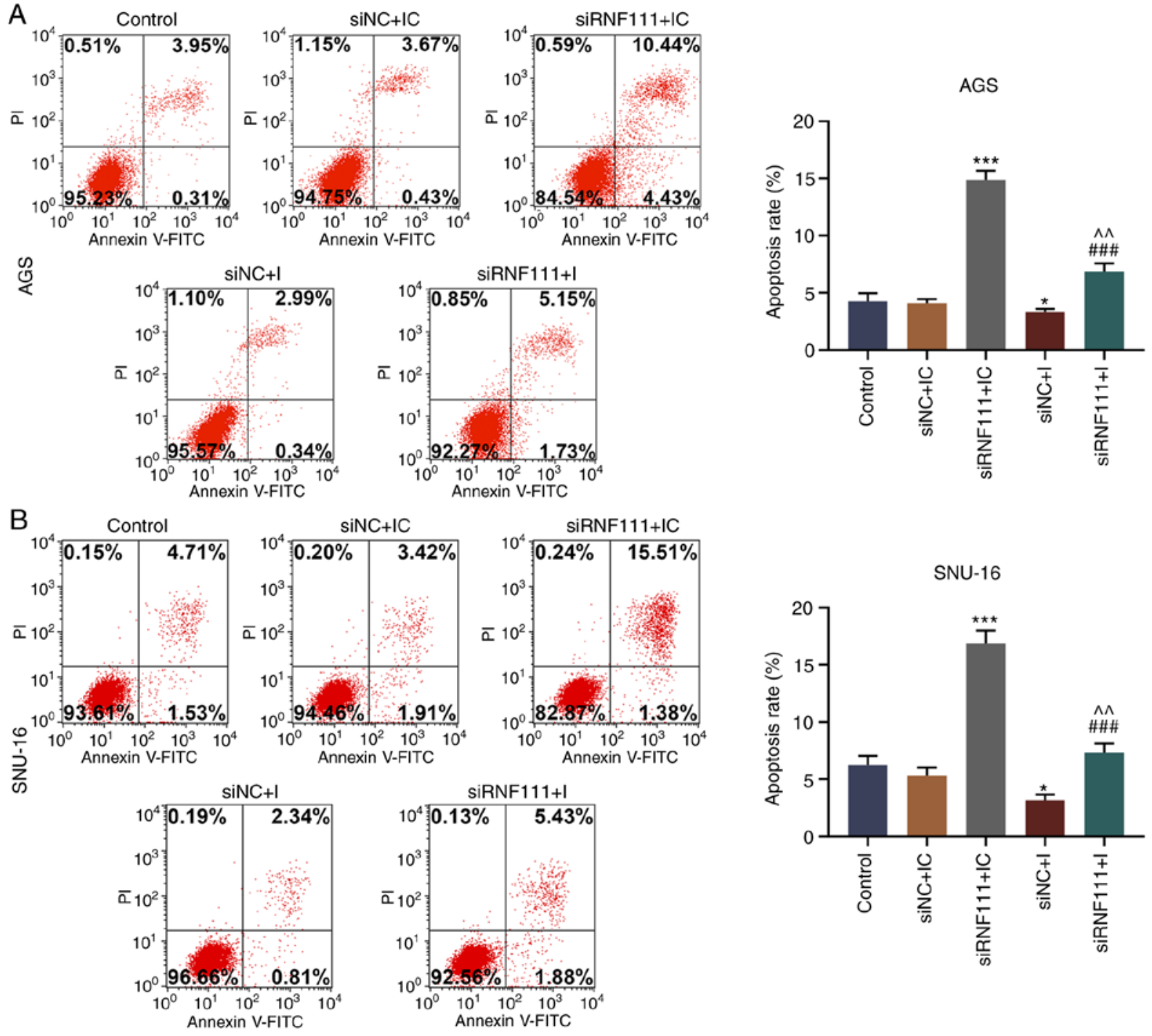

Figure 5. Effects of circRNA RNF111 and miR-27b-3p on the apoptosis of GC cells. (A) Flow cytometry was performed to detect the apoptosis of AGS cells transfected with Control, siNC + inhibitor control, siRNF111 + inhibitor control, siNC + inhibitor, siRNF111 + inhibitor. (B) Flow cytometry was performed to detect the apoptosis of SNU-16 cells transfected with Control, siNC + inhibitor control, siRNF111 + inhibitor control, siNC + inhibitor, siRNF111 + inhibitor ${ }^{*} \mathrm{P}<0.05,{ }^{* * * *} \mathrm{P}<0.001$ vs. siNC + IC, ${ }^{\# \# \#} \mathrm{P}<0.001$ vs. siRNF111 + IC, ${ }^{\wedge} \mathrm{P}<0.01$ vs. siNC + I. GC, gastric cancer; IC, inhibitor control; I, inhibitor.

To further explore the molecular mechanisms of circR-RNF111 and miR-27b-3p in GC metastasis, the expression levels of apoptosis-related and EMT-related proteins were detected by western blot analysis. The results revealed that circRNA RNF111 silencing significantly decreased the expression levels of Bcl2, Vimentin and $\mathrm{N}$-cadherin, and increased and E-cadherin expression; however, miR-27b-3p inhibition significantly reversed the regulatory effects of circRNA RNF111 silencing ( $\mathrm{P}<0.05$; Fig. 8A and $\mathrm{D})$. In addition, circRNA RNF111 silencing significantly increased the expression of cleaved caspase-3, whereas miR-27b-3p inhibition significantly decreased cleaved caspase- 3 expression and reversed the regulatory effects of circRNA RNF111 silencing $(\mathrm{P}<0.05$; Fig. 8B, C, $\mathrm{E}$ and $\mathrm{F}$ ). However, no significant differences were observed in the expression of procaspase 3 in each group.

\section{Discussion}

GC is a malignant tumor with the fourth highest incidence and the third highest mortality rate worldwide (1). The mechanisms of GC occurrence and progression are highly complex, implicating several aspects of cell biology and molecular biology, such as alterations in the adhesion of tumor cells, detachment from primary tumors, and the degradation of the extracellular matrix, local or vascular infiltration (17). With the development of high-throughput sequencing technology and bioinformatics analysis, circRNAs have gradually become a main focus of tumor studies (18).

The association between circRNAs and the proliferation, invasion and metastasis of GC cells has been investigated (19-21). In the present study, circRNA RNF111 and miR-27b-3p were found closely related to tumor size, stage, lymphatic metastasis, distant metastasis and invasion. Li et al reported that in GC tissues, the expression of circRNA002059 was significantly decreased compared to adjacent normal tissues, and an association between the low expression of circRNA and distant metastasis was observed (22). Chen et al detected the expression of circPVT1 in GC tissues and adjacent normal tissues by RT-qPCR (23), and found that the expression of circPVT1 in GC tissues was significantly higher 


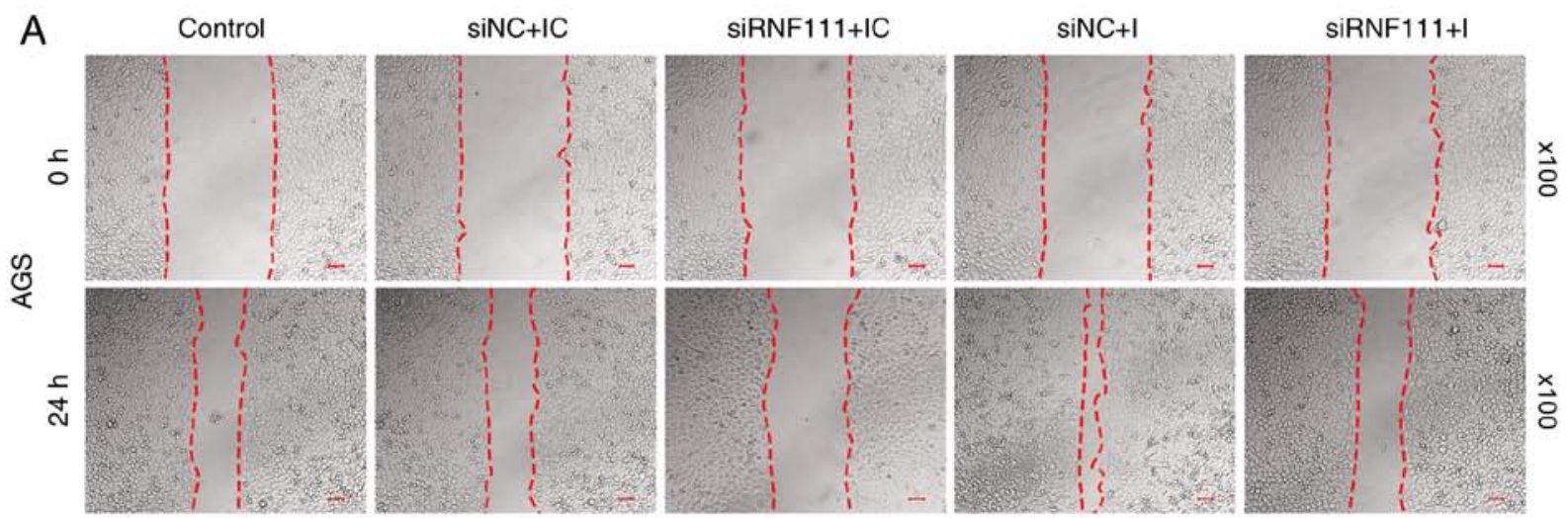

AGS

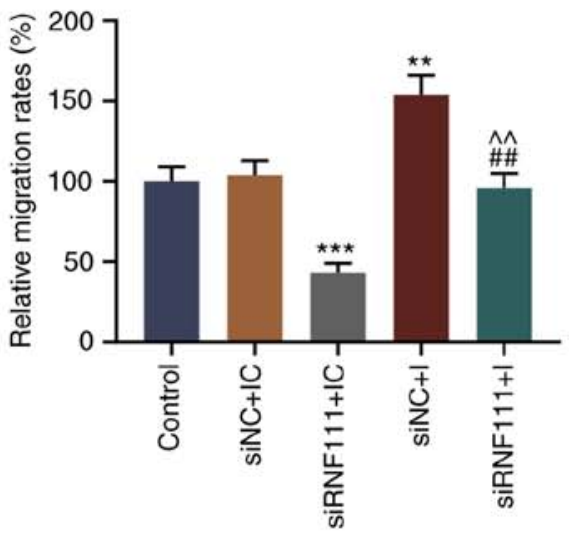

B

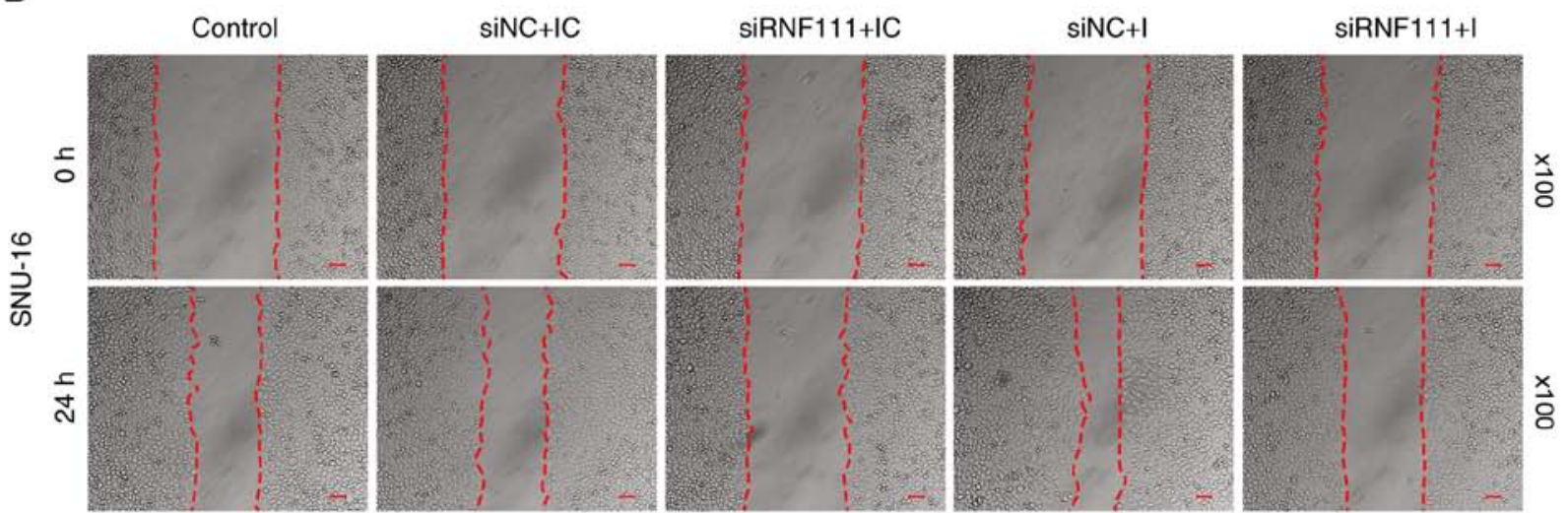

SNU-16

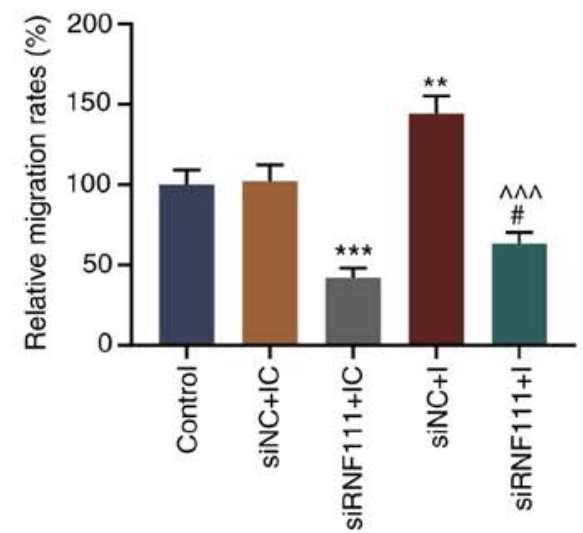

Figure 6. Effects of circRNA RNF111 and miR-27b-3p on GC cell migration. (A) Migratory ability of AGS cells following transfection with Control, siNC + inhibitor control, siRNF111 + inhibitor control, siNC + inhibitor, siRNF111 + inhibitor was determined by wound healing assay. (B) Migratory ability of SNU-16 cells following transfection with Control, siNC + inhibitor control, siRNF111 + inhibitor control, siNC + inhibitor, siRNF111 + inhibitor was determined by wound healing assay. Scale bars, $50 \mu \mathrm{m}$. ${ }^{* *} \mathrm{P}<0.01,{ }^{* * * *} \mathrm{P}<0.001$ vs. siNC $+\mathrm{IC},{ }^{\#} \mathrm{P}<0.05,{ }^{\# \#} \mathrm{P}<0.01 \mathrm{vs}$. siRNF111 + IC, ${ }^{\wedge} \mathrm{P}<0.01,{ }^{\wedge \wedge} \mathrm{P}<0.001 \mathrm{vs}$. siNC $+\mathrm{I}$. GC, gastric cancer; IC, inhibitor control; I, inhibitor. 
A

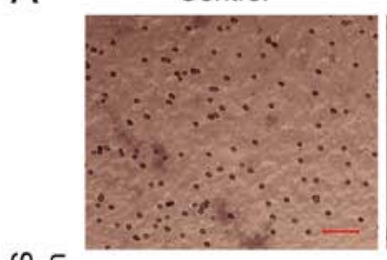

迹迹

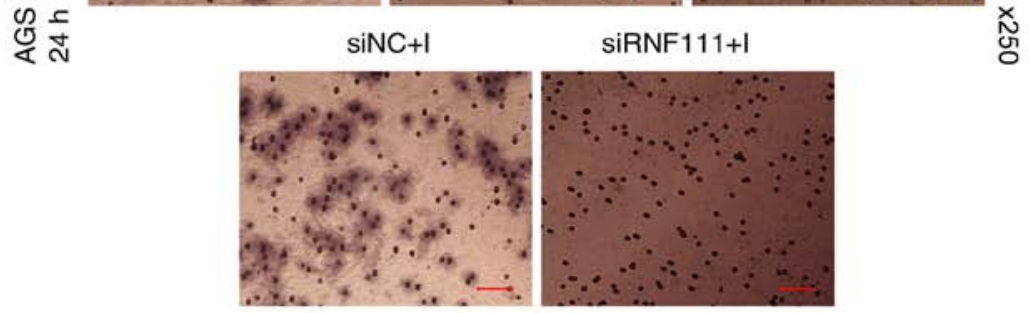

B

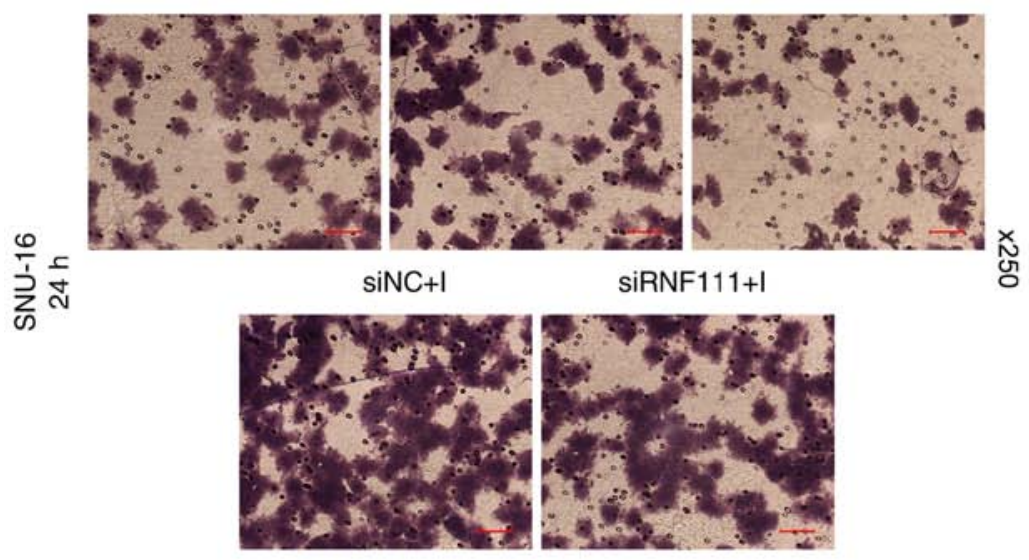

siNC+IC
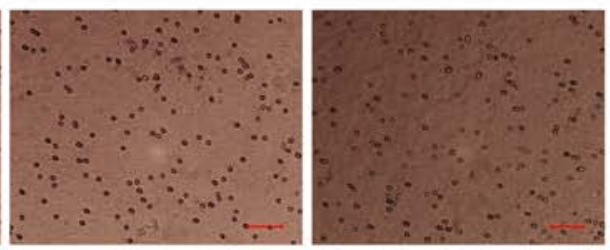

桸

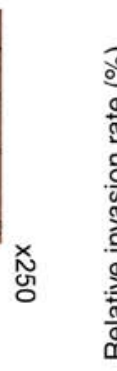

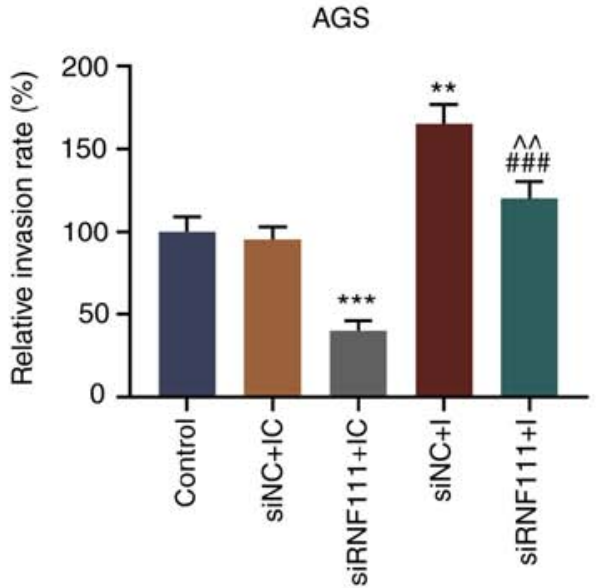

SNU-16

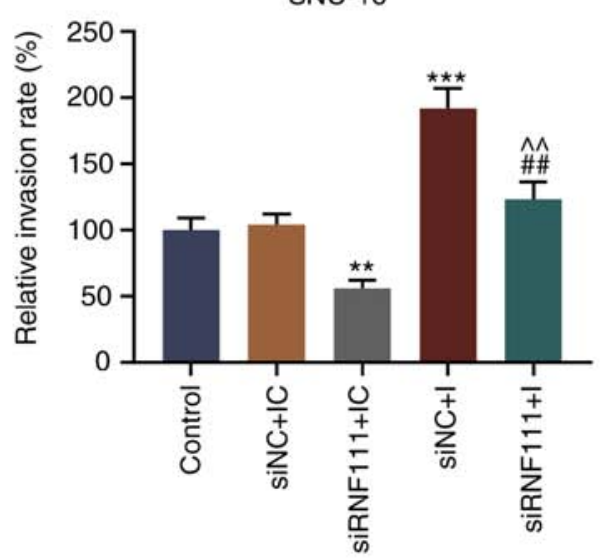

Figure 7. Effects of circR-RNF111 and miR-27b-3p on GC cell invasion. (A) Detection of the invasive ability of AGS cells by Transwell assay following transfection with Control, siNC + inhibitor control, siRNF111 + inhibitor control, siNC + inhibitor, siRNF111 + inhibitor. (B) Detection of the invasion of SNU-16 cells by Transwell assay following transfection with Control, siNC + inhibitor control, siRNF111 + inhibitor control, siNC + inhibitor, siRNF111 + inhibitor. Scale bars, $50 \mu \mathrm{m} .{ }^{* *} \mathrm{P}<0.01,{ }^{* * *} \mathrm{P}<0.001$ vs. siNC $+\mathrm{IC},{ }^{\# \#} \mathrm{P}<0.01,{ }^{\# \# \#} \mathrm{P}<0.001$ vs. siRNF111 + IC, ${ }^{\wedge} \mathrm{P}<0.01$ vs. siNC + I. GC, gastric cancer; IC, inhibitor control; I, inhibitor.

than that in adjacent normal tissues (23). The expression levels of different circRNAs in GC are not necessarily the same (24). In the present, it was found that circRNA RNF111 was significantly highly expressed in GC tissues and cell lines compared with normal tissues and cells. According to a previous study, circRNAs can exert perform their biological functions by interacting with miRNAs (24). For example, Zheng et al found that circHIPK3 derived from HIPK3 gene Exon2 bound to 9 miRNAs with 18 potential binding sites; moreover, it was found to specifically bind to miR-124 to inhibit its activity, and promote tumor cell proliferation (25). Differentially expressed genes, such as CD44, CXXC5, MYH9 and MALAT1 can promote the occurrence of GC through various mechanisms, such as the interactions between circRNAs and miRNAs, and between miRNAs and mRNAs (26). Some scholars have found that miR-27b-3p is involved in the development of GC, and that it is also involved in other types of cancer, such as lung cancer $(27,28)$. miR-27b-3p is abnormally expressed at low levels in GC tissues and negatively correlates with circRNA RNF111. circRNAs function as a competitive endogenous RNAs of miRNAs $(6,7)$. The molecular mechanism underlying the biological role of circRNA RNF111 in GC were further detected in the present study. StarBase predicted that circRNA RNF111 contained a miR-27b-3p specific binding site, which was confirmed by dual luciferase assay. The data indicated that circRNA RNF111 bound to miR-27b-3p to reduce the activity of miR-27b-3p and was involved in the development of GC.

Tumor cells can secrete specific receptors and chemokines to create a cell microenvironment facilitating their own proliferation, invasion into surrounding normal cells and distant metastasis $(4,17)$. The role of RNF111 in lung cancer has been investigated by scholars, and it has been found that RNF111 promotes cancer growth and plays a key role in early cancer cell metastasis (29); however, its functions vary in different types of cancer (30). For example, RNF111 has been shown to exert an inhibitory effect on colon cancer metastasis (31). circR-RNF111 is generated from the RNF111 gene region. In 2013, some scholars identified a large number of circular RNAs, including circRNA RNF111 (32,33), and circRNA RNF111 was then found to be involved in physiological and pathological processes $(34,35)$. Tang et al found that circRNA RNF111 was closely related to the occurrence of breast cancer (13). However, to date, circRNA RNF111 has rarely been reported in GC, at least to the bests of our knowledge. According to previous studies, it was hypothesized that circRNA RNF111 may indirectly increase the expression levels of miR-27b-3p-related target genes by binding to miR-27b-3p, and is involved in the regulation of GC. Unexpectedly, the silencing circRNA RNF111 significantly 

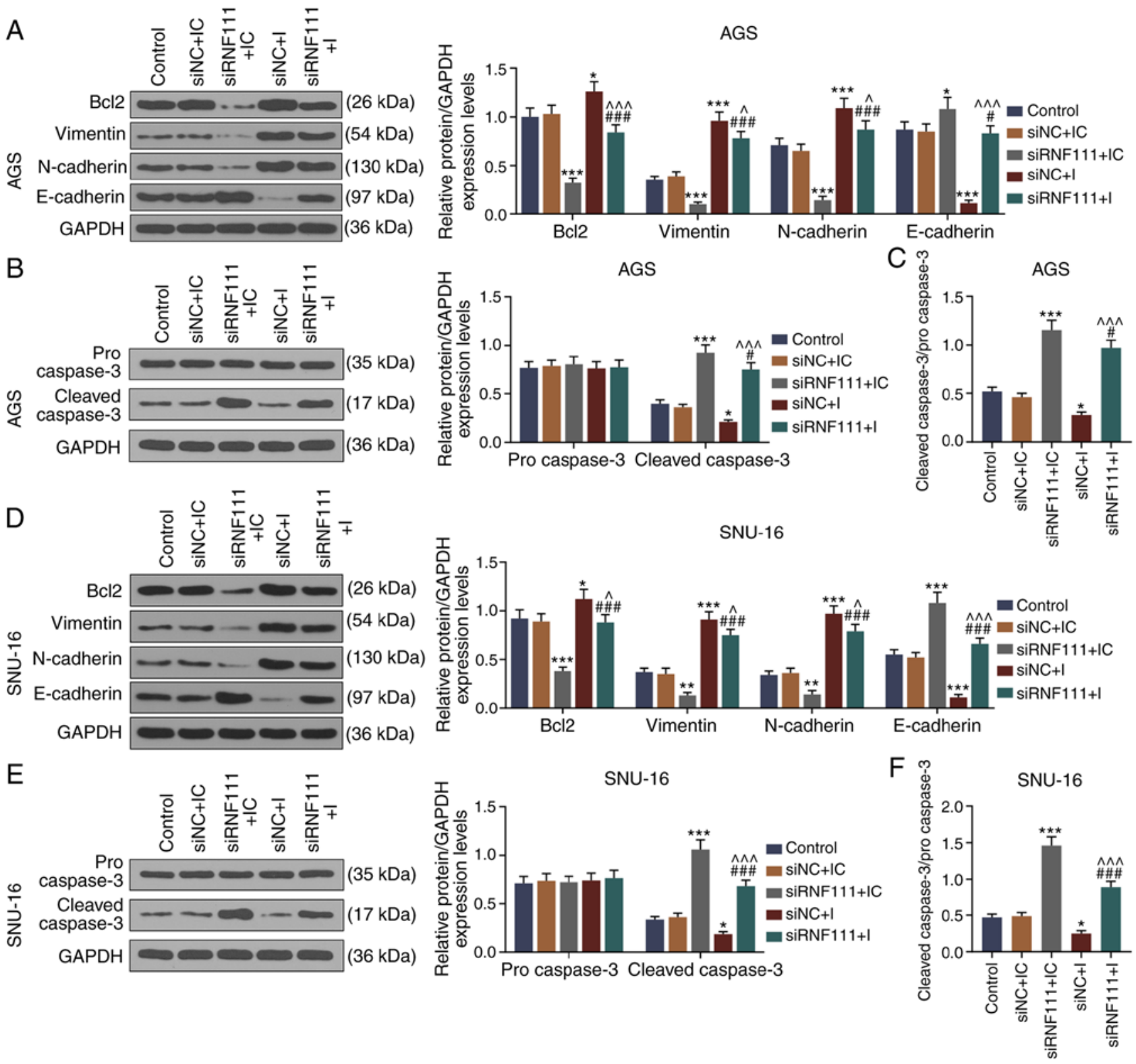

Figure 8. Effects of circRNA RNF111 and miR-27b-3p on the expression of apoptosis, EMT-related proteins in GC cells. (A) Western blot analysis was used to detect the expressions of Bcl2, Vimentin, N-cadherin and E-cadherin in AGS cells following transfection with Control, siNC + inhibitor control, siRNF111 + inhibitor control, siNC + inhibitor, siRNF111 + inhibitor. (B) Western blot analysis was used to detect the expression levels of procaspase-3 and cleaved caspase-3 in AGS cells following transfection with Control, siNC + inhibitor control, siRNF111 + inhibitor control, siNC + inhibitor, siRNF111 + inhibitor. (C) Ratio of cleaved caspase-3/procaspase-3. (D) Western blot analysis was used to detect the expression levels of Bcl2, Vimentin, N-cadherin and E-cadherin in SNU-16 cells following transfection with Control, siNC + inhibitor control, siRNF111 + inhibitor control, siNC + inhibitor, siRNF111 + inhibitor. (E) Western blot analysis was used to detect the expression level of procaspase-3 and cleaved caspase-3 in SNU-16 cells after the transfection with Control, siNC + inhibitor control, siRNF111 + inhibitor control, siNC + inhibitor, siRNF111 + inhibitor. (F) Ratio of cleaved caspase-3/procaspase-3. ${ }^{*} \mathrm{P}<0.05,{ }^{* *} \mathrm{P}<0.01,{ }^{* * * *} \mathrm{P}<0.001 \mathrm{vs}$. siNC + IC, ${ }^{\#} \mathrm{P}<0.05,{ }^{\# \# \#} \mathrm{P}<0.001$ vs. siRNF111 + IC, ${ }^{\wedge} \mathrm{P}<0.05,{ }^{\wedge \wedge} \mathrm{P}<0.001$ vs. siNC + I. GC, gastric cancer; IC, inhibitor control; I, inhibitor.

inhibited the proliferation and metastasis of GC cells and exerted a pro-apoptotic effect. miR-27b-3p inhibition significantly promoted the proliferation and metastasis of GC cells, and inhibited apoptosis, indicating the biological functions of circRNA RNF111 and miR-27b-3p in GC. As an anti-apoptotic member of the Bcl protein family, Bcl-2 plays a role in maintaining the apoptotic-anti-apoptotic balance (36). The cascade reaction produced by the caspase family is the central link of apoptosis. Activated caspase- 3 hydrolyzes the target substance in cells, thereby degrading the intracellular protein and finally causing apoptosis (36). E-cadherin and N-cadherin are two proteins indicative of epithelial-mesenchymal transition
(EMT) $(37,38)$. Tumor epithelial cells transform to interstitial cells, resulting in an invasive phenotype and easy distant metastasis (39). The present study further examined the functions of circRNA RNF111 and miR-27b-3p at the molecular level, and detected the expression levels of Bcl2, cleaved caspase-3, Vimentin, N-cadherin and E-cadherin in GC cells, and the findings revealed that circRNA RNF111 may be involved in GC apoptosis and metastasis by targeting miR-27b-3p to regulate apoptosis and EMT-related pathways.

It should be noted that the present study has some limitations. The effects of circRNA RNF111/miR-27b-3p on the cell cycle of GC remain to be analyzed. In addition, the effects 
of silencing circRNA RNF111 on inhibiting the proliferation, migration and invasion of GC cells should be confirmed by in vivo experiments.

In conclusion, the present study demonstrated that circRNA RNF111 was highly expressed in GC cells and tissues. circRNA RNF111 was found to regulate GC cell growth and metastasis possibly by targeting miR-27b-3p, suggesting that circRNA RNF111 and miR-27b-3p are potential targets for the treatment of GC.

\section{Acknowledgements}

Not applicable.

\section{Funding}

The present was supported by the 2017 Medical Science and Technology Development Program of Nanjing (grant no. YKK17108).

\section{Availability of data and materials}

The analyzed datasets generated during the study are available from the corresponding author on reasonable request.

\section{Authors' contributions}

$\mathrm{ZW}$ and $\mathrm{ZJ}$ made substantial contributions to conception and design of the study. ZW, ZJ, JZ and ZL were involved in data acquisition, data analysis and interpretation. ZW and ZJ drafted the article or critically revised it for important intellectual content. All authors gave the final approval of the final version of the manuscript to be published. All authors also agree to be accountable for all aspects of the work in ensuring that questions related to the accuracy or integrity of the work are appropriately investigated and resolved.

\section{Ethics approval and consent to participate}

All patients had signed informed consent forms, and agreed that their tissues would be used for clinical research. The clinical trial program had been reviewed and approved by the Ethics Committee of Nanjing First Hospital (W201810013). No animals are involved in this research.

\section{Patient consent for publication}

Not applicable.

\section{Competing interests}

The authors declare that they have no competing interests.

\section{References}

1. Correa P: Gastric cancer: Overview. Gastroenterol Clin North Am 42: 211-217, 2013.

2. Karimi P, Islami F, Anandasabapathy S, Freedman ND and Kamangar F: Gastric cancer: Descriptive epidemiology, risk factors, screening, and prevention. Cancer Epidemiol Biomarkers Prev 23: 700-713, 2014.
3. Ang TL and Fock KM: Clinical epidemiology of gastric cancer. Singapore Med J 55: 621-628, 2014.

4. Sano T: Gastric cancer: Asia and the world. Gastric Cancer 20 (Suppl 1): S1-S2, 2017.

5. Greene J, Baird AM, Brady L, Lim M, Gray SG, McDermott R and Finn SP: Circular RNAs: Biogenesis, function and role in human diseases. Front Mol Biosci 4: 38, 2017.

6. Patop IL and Kadener S: circRNAs in cancer. Curr Opin Genet Dev 48: 121-127, 2018

7. Rong D, Sun H, Li Z, Liu S, Dong C, Fu K, Tang W and Cao H: An emerging function of circRNA-miRNAs-mRNA axis in human diseases. Oncotarget 8: 73271-73281, 2017.

8. Zhong Z, Huang M, Lv M, He Y, Duan C, Zhang L and Chen J: Circular RNA MYLK as a competing endogenous RNA promotes bladder cancer progression through modulating VEGFA/VEGFR2 signaling pathway. Cancer Lett 403: 305-317, 2017.

9. Ashwal-Fluss R, Meyer M, Pamudurti NR, Ivanov A, Bartok O, Hanan M, Evantal N, Memczak S, Rajewsky N and Kadener S: circRNA biogenesis competes with pre-mRNA splicing. Mol Cell 56: 55-66, 2014.

10. Han D, Li J, Wang H, Su X, Hou J, Gu Y, Qian C, Lin Y, Liu X, Huang M, et al: Circular RNA circMTO1 acts as the sponge of microRNA-9 to suppress hepatocellular carcinoma progression. Hepatology 66: 1151-1164, 2017.

11. Bernardo BC, Ooi JY, Lin RC and McMullen JR: miRNA therapeutics: A new class of drugs with potential therapeutic applications in the heart. Future Med Chem 7: 1771-1792, 2015.

12. Shin VY and Chu KM: MiRNA as potential biomarkers and therapeutic targets for gastric cancer. World J Gastroenterol 20: 10432-10439, 2014.

13. Tang YY, Zhao P, Zou TN, Duan JJ, Zhi R, Yang SY, Yang DC and Wang XL: Circular RNA hsa_circ_0001982 promotes breast cancer cell carcinogenesis through decreasing miR-143. DNA Cell Biol 36: 901-908, 2017.

14. Fang Q, Chen X and Zhi X: Long non-coding RNA (LncRNA) urothelial carcinoma associated 1 (UCA1) increases multi-drug resistance of gastric cancer via downregulating miR-27b. Med Sci Monit 22: 3506-3513, 2016.

15. Singh C and Roy-Chowdhuri S: Quantitative real-time PCR: Recent advances. Methods Mol Biol 1392: 161-176, 2016.

16. Kurien BT and Scofield RH: Western blotting: An introduction. Methods Mol Biol 1312: 17-30, 2015.

17. Röcken C: Molecular classification of gastric cancer. Expert Rev Mol Diagn 17: 293-301, 2017.

18. Patop IL, Wüst S and Kadener S: Past, present, and future of circRNAs. EMBO J 38: e100836, 2019.

19. Zhang Y, Liu H, Li W, Yu J, Li J, Shen Z, Ye G, Qi X and Li G: CircRNA_100269 is downregulated in gastric cancer and suppresses tumor cell growth by targeting miR-630. Aging (Albany NY) 9: 1585-1594, 2017.

20. Tang W, Fu K, Sun H, Rong D, Wang H and Cao H: CircRNA microarray profiling identifies a novel circulating biomarker for detection of gastric cancer. Mol Cancer 17: 137, 2018.

21. Shao Y, Li J, Lu R, Li T, Yang Y, Xiao B and Guo J: Global circular RNA expression profile of human gastric cancer and its clinical significance. Cancer Med 6: 1173-1180, 2017.

22. Li P, Chen S, Chen H, Mo X, Li T, Shao Y, Xiao B and Guo J: Using circular RNA as a novel type of biomarker in the screening of gastric cancer. Clin Chim Acta 444: 132-136, 2015.

23. Chen J, Li Y, Zheng Q, Bao C, He J, Chen B, Lyu D, Zheng B, $\mathrm{Xu}$ Y, Long Z, et al: Circular RNA profile identifies circPVT1 as a proliferative factor and prognostic marker in gastric cancer. Cancer Lett 388: 208-219, 2017.

24. Arnaiz E, Sole C, Manterola L, Iparraguirre L, Otaegui D and Lawrie CH: CircRNAs and cancer: Biomarkers and master regulators. Semin Cancer Biol 58: 90-99, 2019.

25. Zheng Q, Bao C, Guo W, Li S, Chen J, Chen B, Luo Y, Lyu D, Li Y, Shi G, et al: Circular RNA profiling reveals an abundant circHIPK3 that regulates cell growth by sponging multiple miRNAs. Nat Commun 7: 11215, 2016.

26. Sui W, Shi Z, Xue W, Ou M, Zhu Y, Chen J, Lin H, Liu F and Dai Y: Circular RNA and gene expression profiles in gastric cancer based on microarray chip technology. Oncol Rep 37: 1804-1814, 2017.

27. Tao J, Zhi X, Zhang X, Fu M, Huang H, Fan Y, Guan W and Zou C: miR-27b-3p suppresses cell proliferation through targeting receptor tyrosine kinase like orphan receptor 1 in gastric cancer. J Exp Clin Cancer Res 34: 139, 2015. 
28. Sun Y, Xu T, Cao YW and Ding XQ: Antitumor effect of miR-27b-3p on lung cancer cells via targeting Fzd7. Eur Rev Med Pharmacol Sci 21: 4113-4123, 2017.

29. Hedrick E, Mohankumar K and Safe S: TGF $\beta$-induced lung cancer cell migration is NR4A1-dependent. Mol Cancer Res 16 : 1991-2002, 2018.

30. Chen H, Yang T, Lei Z, Wang L, Yang H, Tong X, Yang WT, Zhao J, Gu Y, Chen Y and Zhang HT: RNF111/Arkadia is regulated by DNA methylation and affects TGF- $\beta /$ Smad signaling associated invasion in NSCLC cells. Lung Cancer 90: 32-40, 2015.

31. Sharma V, Antonacopoulou AG, Tanaka S, Panoutsopoulos AA Bravou V, Kalofonos HP and Episkopou V: Enhancement of TGF- $\beta$ signaling responses by the E3 ubiquitin ligase arkadia provides tumor suppression in colorectal cancer. Cancer Res 71 6438-6449, 2011.

32. Jeck WR, Sorrentino JA, Wang K, Slevin MK, Burd CE, Liu J, Marzluff WF and Sharpless NE: Circular RNAs are abundant, conserved, and associated with ALU repeats. RNA 19: 141-157, 2013.

33. Salzman J, Chen RE, Olsen MN, Wang PL and Brown PO: Cell-type specific features of circular RNA expression. PLoS Genet 9: e1003777, 2013.

34. Rybak-Wolf A, Stottmeister C, Glažar P, Jens M, Pino N, Giusti S, Hanan M, Behm M, Bartok O, Ashwal-Fluss R, et al: Circular RNAs in the mammalian brain are highly abundant, conserved, and dynamically expressed. Mol Cell 58: 870-885, 2015.
35. Maass PG, Glažar P, Memczak S, Dittmar G, Hollfinger I, Schreyer L, Sauer AV, Toka O, Aiuti A, Luft FC and Rajewsky N: A map of human circular RNAs in clinically relevant tissues. J Mol Med (Berl) 95: 1179-1189, 2017.

36. Li H, Lv B, Kong L, Xia J,Zhu M, Hu L, Zhen D, Wu Y, Jia X, Zhu S and Cui H: Noval mediates resistance of rat pheochromocytoma cells to hypoxia-induced apoptosis via the $\mathrm{Bax} / \mathrm{Bcl}-2 /$ caspase-3 pathway. Int J Mol Med 40: 1125-1133, 2017.

37. Petrova YI, Schecterson L and Gumbiner BM: Roles for E-cadherin cell surface regulation in cancer. Mol Biol Cell 27: 3233-3244, 2016.

38. Derycke LD and Bracke ME: N-cadherin in the spotlight of cell-cell adhesion, differentiation, embryogenesis, invasion and signalling. Int J Dev Biol 48: 463-476, 2004.

39. Lamouille S, Xu J and Derynck R: Molecular mechanisms of epithelial-mesenchymal transition. Nat Rev Mol Cell Biol 15: 178-196, 2014.

This work is licensed under a Creative Commons Attribution-NonCommercial-NoDerivatives 4.0 International (CC BY-NC-ND 4.0) License. 